\title{
Evaluating Graduate Students within an Online Literacy Clinic: Providing Practicum Experiences for Candidates Who are Pursuing Graduate Studies in the Reading Teacher Endorsement and the Reading Specialist
}

\author{
Chhanda Islam, PhD \\ Murray State University \\ Professor, Department of Early Childhood and Elementary Education \\ 3213 Alexander Hall, Murray State University \\ Murray, KY 42071, USA
}

\begin{abstract}
Graduate students who want to be literacy specialists are required by the state to complete a practicum in a literacy clinic under the supervision of their instructor. A recent trend involves moving literacy clinics to an online delivery that includes both synchronous and asynchronous collaboration (Lilienthal, 2014; Lilienthal et al., 2017). By offering a practicum course online, colleges can increase access to educational and professional growth opportunities for those students who are geographically constrained (Frey, 2008). Technology becomes even more critical for a literacy clinical course because the instructor must be able to not only deliver the course content online but also supervise students as they teach children in educational settings. This study explored how technologies and other aspects of an online literacy practicum course delivery worked in terms of supporting the quality of learning and increasing the efficacy of graduate students. Findings revealed that the technologies and other aspects of an online literacy practicum course delivery supported the quality of learning and increased the efficacy of graduate students. These findings are consistent with previous research that described the process of moving a literacy clinic online in order to offer the highest level of efficacy (Bodzin \& Park 2016; Caywood \& Duckett, 2019; Vokatis, 2018).
\end{abstract}

\section{Introduction}

Many higher education institutions in the United States offer both graduate and undergraduate coursework online through synchronous and asynchronous learning communities, including entire programs of study that range from liberal arts, to humanities, to professional degrees (Allen \& Seaman, 2013). The most recent data suggest the trend will continue since online enrolment in the United States has continued to grow (Allen \& Seaman, 2013). A similar trend can be seen in literacy education courses, where entire Literacy Specialist Endorsement P-12 master's programs are being offered online through hybrid and blended courses formed to broaden opportunities for master's students.

For more than a decade, distance learning has been a part of higher education in every postsecondary institution. Administrators who once thought that an instructor's physical presence in a classroom contributed to the success of the students and the program, both pedagogically and economically, are now encouraging their academic faculty members to teach via video conferencing - a viable alternative (Peterson \& Slotta, 2009). To expand offerings, bolster enrolment and revenue streams, and reach remote students, many administrators are willing to offer webenhanced courses because they think technology-based classrooms can produce better results than the conventional classroom. Such views are supported by many researchers who suggest distance teaching and learning can be equal to or better than in-person teaching in a traditional classroom (Karabulut \& Correia, 2008). A web-enhanced course is classified as an online class wherein face-to-face instruction is integrated with internet-based activities that substitute for a substantial amount of "seat time" in the traditional classroom. Ultimately, the goal of hybrid instruction is to create synchronous and asynchronous learning communities that enable students to create networks of interaction in which deep learning takes place (Li \& Akins, 2005; Wang \& Newlin, 2000).

Graduate students who want to be literacy specialists are required by the state to complete a practicum in a literacy clinic under the supervision of their instructor. A recent trend has involved moving literacy clinics to online delivery that includes both synchronous and asynchronous collaboration (Lilienthal, 2014; Lilienthal et al., 2017). By offering a practicum course online, colleges can increase access to educational and professional growth opportunities for those who are geographically constrained (Frey, 2008).

The two main purposes of literacy clinics are to serve the districts and to provide supervised instructional experiences for graduate students. 
Supervised instructional experiences help graduate students develop knowledge, skills, and abilities to administer literacy assessments and instruction that will improve young children's reading and writing abilities (Atkinson \& Colby, 2006). These literacy instructional experiences carry common themes of instruction in fluency, word study, and comprehension, although each literacy tutoring session allocates different amounts of time and implements a variety of instructional concepts for each of these areas of literacy (Coulter, 2004; Houge et al., 2008; Manset-Williamson \& Nelson, 2005; Penney, 2002).

Technology, a critical aspect of online teaching, becomes even more critical and complex when teaching a literacy clinic course because graduate students are required to tutor children in a literacy clinic, and the instructor is responsible for both delivering the course content and supervising the practicum. However, it is difficult to find a systematic empirical study of how the collaborative competencies of graduate students and course instructors impact literacy learning in a practicum course offered through synchronous and asynchronous learning communities(Bodzin \& Park, 2016).This study reflected on how technologies and other aspects of an online literacy practicum course delivery worked in terms of supporting the quality of learning and increasing the efficacy of graduate students.

\section{The Research}

In the online literacy clinic course, instructor and graduate students do not meet facetoface; instead, the instructor provides instructions via synchronous and asynchronous communications (Vokatis, 2018). In addition, in this type of delivery, the instructor supervises graduate students as they tutor children remotely - for instance, by watching graduate students instructing children via Zoom or a YouTube channel. Thus far, the latest innovation when moving literacy clinics to an online mode is mostly limited to a description of course design using course management systems such as Blackboard (Lilienthal, 2014). In addition, some literature espouses certain technologies, such as Skype and high-speed internet (Sanders, 2014), for supervising an online clinic. Moreover, Helfrich and Smith (2011) provided general ideas of preparation for going online, including appropriate technologies used for course content teaching and for fieldwork. However, a rigorous online clinic for increasing graduate students' efficacy that explores the latest technologies that can be used by graduate students to easily record their tutoring and share with the course instructors is not described in the literature. Therefore, this research provides insight into these areas, specifically focusing on the incorporation of Canvas and Zoom into an online literacy clinic course.

The asynchronous format of web conferences via Canvas, a learning management system software, allows graduate students to become creative and innovative because they have more time to prepare a response to a set of directions or questions. Moreover, synchronous systems used in conjunction with asynchronous tools can create an online learning community that provides support to students from both peers and instructors because the web-enhanced classes boost the interaction and create a sense of connectedness among students (Beattie et al., 2017). Web conferencing via Zoom has been proven effective not only in delivering course content but also in developing a rigorous online literacy clinic for increasing graduate students' efficacy. For example, web conferencing via Zoom can serve as a collaborative tool to allow graduate students from widely dispersed communities to share tutoring experiences and engage in joint problem-solving in real-life classroom situations. When used in university coursework and practicum session activities, it can be comparable to having face-to-face discussions in a conventional class setting.

\section{Online Literacy Clinic Course}

The graduate online literacy clinic course was designed to prepare graduate students to use assessment data to design applicable intervention and remediation for students with literacy difficulties in Grades $\mathrm{P}-12$. The course also provides graduate students with approaches and techniques that have been proven successful through research and practice. The basic premise of this course is to allow graduate students to implement a variety of research-based reading strategies to build the literacy skills of struggling readers. Graduate students are encouraged to incorporate technology-enriched instruction that encourages $\mathrm{P}-12$ students to use newer, more sophisticated tools, such as electronic books, interactive software, integrated media, and problem-solving applications (McKenna \& Walpole, 2019).

The course was offered as a web-enhanced course for 3 credit hours. It was separated into two categoriesasynchronous and synchronous - so graduate students experienced both conditions: synchronous interactive web conferencing lectures and asynchronous text-based lectures (Caywood \& Duckett, 2019). Instructors used online tools to create a web-enhanced course in which one-third of the sessions were offered through Canvas asynchronous online learning (text-based, using discussion boards), and two-thirds of the sessions were offered through the newer web synchronous conferencing tool Zoom. 
A typical class week included the graduate students downloading text-based lecture notes (e.g., PowerPoint, Google or Word document), reading a chapter in the textbook to correspond with the lecture notes, and responding on a discussion board by the end of the week. All course content was available for graduate students in an asynchronous format and organized by Canvas module tools (Caywood \& Duckett, 2019). Web conferencing lectures were structured to mirror a face-to-face classroom. The interactive nature of the Zoom instructional tools provided a real-time virtual classroom by using two-way audio, a webcam, breakout rooms, a chat window, and application sharing.

The researcher used the online discussion board on Canvas to hold online discussions about the tutoring sessions. Thus, the graduate students in the literacy clinic used Canvas discussions as a time to reflect, integrate their learning and their practice, and seek advice from their colleagues. Multimedia expanded the opportunity for graduate students to develop a community of learners who reflected and collaborated on a variety of reading and writing experiences and shared their best practices, concerns, and pressing challenges while working with their tutees. The reflections served two purposes. First, the researcher wanted to stimulate reflective conversation among the graduate students regarding their work with tutees. Second, the postings on Canvas helped the researcher meet the short-term needs of the graduate students and provided insight into how the literacy clinic might further be restructured to better prepare graduate students for their role as reading specialists (Vokatis, 2018).

\section{The Literacy Clinic and Tutoring}

The participants studying to become reading specialists tutored struggling readers in one-on-one sessions and were required to make significant use of technology in their instruction (McKenna \& Walpole, 2019). The sessions were designed to increase the comprehension, fluency, and sight word vocabulary of the tutees and to develop language and thinking skills. The program offered activities that used reading and rereading texts, cognitively challenging talk, discussion of vocabulary words, summarization of texts, evaluative responses about texts, and connections between texts and real-life experiences (Atkinson \& Colby, 2006). The graduate students used in-depth assessment and flexibility in adapting instructional techniques to meet individual differences and needs. Potential stumbling blocks were identified that might impede tutees on the journey to be skilled readers. Assessment revealed several issues facing tutees. For example, one-third of the tutees were unable to understand the use of the alphabetic principle - the idea that written spellings systematically represent spoken words. Seventy-five percent of the tutees had difficulty comprehending connected text or recognizing difficult words. One-third of the tutees could not transfer the comprehension skills of spoken language to reading or struggled to acquire new strategies that could be used with a wide variety of texts. Some lacked the motivation to read or had failed to develop an appreciation ofthe value of reading.

Graduate students were asked to use YouTube to video-record two tutoring sessions, one in which they interacted with tutees through only reading, and another one in which they implemented software multimedia tools. The purpose of the two types of requested interaction was to get them more focused on quality instruction (Vokatis, 2018), a process enhanced by being able to watch the videos(rewinding when necessary) and analyze interaction in more detail in order to provide written feedback via Canvas.

\section{Feedback on Videos From Tutoring}

Following their work with the children, the graduate students participated in weekly, hour-long meetings with the researcher via Zoom, each of which featured a balance of researcher-led discussions of relevant theoretical implications and tutor-generated discussions and questions raised by their tutoring experiences. The course was designed to give graduate students the opportunity to implement theories into practice as they developed their conceptual understanding and theoretical perspective regarding working with struggling readers. The graduate students needed an opportunity to be productive, reflective, and adaptive literacy leaders while at the same time increasing their knowledge, skills, and abilities to serve as a literacy coach.

Recap (https://edshelf.com/tool/recap/), a multimedia online platform, was used to store graduate students' recorded video reflections. Recording and replaying tutoring film allowed graduate students to see moments of student learning, thereby helping them to understand both what went well in a lesson and what they could improve upon next time. Reflective practice allowed graduate students to create and experiment with new ideas and approaches to gain maximum efficacy.

The researcher connected with individual graduate students via Zoom when it was time to provide feedback. One of the most important components of the course was when the researcher conversed with individual graduate students about how a tutoring session went. With the help of Canvas technology, the researcher was able to provide students written feedback based on analyses of their video tutoring sessions. 
The aim was to create rich learning experiences for graduate students that have significant effectson tutees' learning outcomes. Other purposes were as follows: (a) to provide collaborative dialogue for graduate students at all levels of knowledge and experience; (b) to use assessments characterized by data-driven instruction to facilitate change in practice; and (c) to develop job-embedded professional learning to increase graduate students' capacity to meet individual students' needs.

\section{Method}

This study employed a qualitative approach to identify relationships between variables (Crossman, 2019).Qualitative data were generated through the use of open questions. The researcher used caution to ensure that personal bias did not influence the data in ways that significantly changed the interpretation of the findings.

The study included nine graduate students who took the practicum course via asynchronous and synchronous learning spaces that used a variety of platforms, including Canvas and Zoom. The ages of the graduate students ranged from 25 to 40 years old. All were White female classroom teachers. Of the nine graduate students, $55 \%$ had taught for 5 years or less, and $45 \%$ had over 5 years of teaching experience.

The instructor/researcher conducted an in-depth interview fall graduate students enrolled in the online course as a voluntary evaluation procedure at the end of the course. The graduate students responded anonymously to the interview questions and were informed that their responses would not affect their course grade. The interviews were digitally recorded for later transcription and coding. The interviews were transcribed and analyzed based on the constant comparative method. The constant comparative qualitative procedure was selected because it "is concerned with generating and plausibly suggesting (but not provisionally testing) many categories, properties, and hypotheses about general problems" (Strauss \& Corbin, 1990, p. 96). The data were then compiled by responses from the nine interviews to compare the experiences. The coded responses were reviewed by the researcher and grouped together into categories.

Data for this study included graduate students' exit reflections on their teaching and learning and on the group discussions that took place on Canvas. The purpose of the reflections was to assess the impact of the class and the progress and needs of the graduate students. The discussion board comments were used to assess the academic and professional expertise of the graduate students. The multimedia Recap computer app was used to share graduate students' reflections via video and audio. The reflections and discussion board responses were evaluated based on whether a student presented ideas that reflected integration of course material and an expansion of the student's pedagogical and content expertise.

\section{Results and Discussion}

This qualitative method study explored how technologies and other aspects of an online practicum course delivery worked in terms of supporting the quality of learning and increasing the efficacy of graduate students. The findings revealed that the pedagogical shifts made by graduate students in an online reading practicum course resulted in (a) an increase in knowledge of data-driven instruction and diagnosis, as evidenced by met cognitive reflection and advanced understandings; (b) the refinement of graduate students' instructional differentiation and intervention skills based on their tutoring experiences, as evidenced through their logical reasoning; and (c) increased commitment to providing diagnostic reading intervention based on formal and informal data-driven instructions. Three strategies emerged from the findings: (1) composing clear articulations of learning objectives, (2)promoting contextualized and individualized learning, and (3) planning for visual and audio representation of concepts(McKenna \& Walpole, 2019).

Findings from this study suggest that one-to-one literacy instruction can be an engaging and effective method to assist $\mathrm{P}-12$ students in attaining appropriate accuracy and fluency while reading for comprehension and meaning (Coulter, 2004). The analysis of the informal assessment scores demonstrated that $\mathrm{P}-12$ students with varying reading and writing abilities and levels of prior knowledge made significant score gains. Although the limited sample size precluded the ability to draw strong conclusions, this qualitative study identified several factors associated with successful outcomes. Some of the important factors for successful implementation of one-to-one literacy clinic included(a) a supportive atmosphere that motivated tutees to participate during tutoring sessions by actively processing the texts and responding to tutors' questions, and (b) more desirable integration strategies during curriculum-based, technology-enhanced field experiences (Vokatis, 2018). 
The technologically integrated tutoring proved valuable in contributing to tutees' ability to comprehend texts. The nine graduate students, who had little experience with technology in teaching and learning, found that the reading methods online practicum course experience eased their computer anxiety and improved their computer proficiency instruction. One graduate student participant, in response to an interview question, indicated that new technology, such as digital text and electronic books, affords rich opportunities for a variety of comprehension strategies during the sessions:

Digital texts are infused with pictures, sometimes interactive, to facilitate learning. My tutee utilized auditory and visual cues to effectively absorb the information. The combination of audio and visual signals resulted in a greater depth of understanding than either alone, which was particularly salient for the tutee, who tended to [over-rely]upon pictures to aid in decoding words and comprehending the text.

Another graduate student took on many new roles, such as collaborating and coaching with fellow classmates and working with a struggling reader to meet International Literacy Association's standards (ILA, 2017):

Since I was able to increase fluency rates and accuracy with focused fluency instruction while meeting ILA Standards 5.2 and 6.3, I feel this literacy clinic was a great success.Initially, my student was averaging 120 words-per-minute at the end of May. Rounded to the nearest whole number, this student made a 15 words-perminute improvement by the middle of May. Accuracy scores improved as the number of errors plummeted from an average of 3.6 errors-per-minute to 1.3 errors-per-minute. I observed that my student's prosody improved with each repeated reading and teacher oral reading modeling session.

The researcher contends that improving the quality of reading instruction can lead to growth in student reading achievement. Likewise, eight out of nine graduate students said that the potential of literacy coaching to collaboratively influence teachers' growth positively impacts their students' learning (Quatroche \& Wepner, 2008). The leadership role emerged as a critical component of literacy coaches because the graduate students assisted teachers/classmates by modeling strategies and suggesting materials that enhance instruction and assessment and by supporting teachers in becoming more knowledgeable about the teaching of reading. From this research, the graduate students gained a better understanding of how to assume a leadership position among their peers. They became more confident in their ability to guide another teacher in his or her pursuit of instructional growth (Quatroche \& Wepner, 2008).

\section{Graduate Student Performance through Discussion Board}

The graduate students used Canvas discussions as a time to reflect, integrate their learning and their practice, and seek advice from other graduate students while tutoring. The discussion board prompts generated 69 postings on Canvas. In 50 out of 69 postings to Canvas, the graduate student participants assisted their colleagues in order to meet the literacy needs of their tutees. In over 20 postings, the graduate students discussed38different activities they found most useful in working with their struggling reader. The nine graduate students scored either a satisfactory performance (3) or higher (4) rating on the assignment rating scale for criteria related to the learning outcome.

As evidenced in the Canvas discussions, the nine graduate student participants asked their classmates for suggestions on literacy strategies tailored to meet specific needs to use with their tutees (Coulter, 2004). The graduate students not only drew upon each other's expertise but also incorporated that knowledge into their own teaching and learning situations with their tutees. Canvas supplied the students a discussion forum in which to reflect on their own instructional strategies as well as adapt other strategies used by their colleagues in the literacy clinic. The Canvas discussion board increased their repertoire of abilities and their knowledge base. Through readings, discussions, and experience with a wide variety of materials on Canvas, these graduate students developed a plethora of strategies to meet the needs of their tutees.

\section{Exit Reflections}

When designing the practicum component, the researcher wanted graduate students to have the opportunity to be able to reflect on their best practices and seek advice from their instructors and their colleagues. Eight out of the nine graduate students achieved an outstanding performance score on the assignment rating scale for criteria related to the learning outcome.

Recap was used to share graduate students' reflections via video and audio. All nine graduate students reported that a video recording of lessons was valuable because it provided an unaltered and unbiased vantage point from which to view-from an instructor's perspective - the effectiveness of their lesson. The videos also acted as an additional set of eyes to catch ineffective literacy strategies that they did not realize were occurring during the tutorials. 
The developed literacy practicum course allowed graduate students to evolve from teachers to literacy specialists. It specifically allowed them time to put theory into practice, to reflect on their own tutoring sessions, and to identify their own challenges in the transformation from teacher to leader.

By creating a system in which participants could support each other's learning and come together as a community, the practicum course created an environment in which the participants were able to draw upon and incorporate each other's expertise. This environment established a setting in which graduate students had the time and opportunity to focus fully on their own and others' instructional practices. Graduate students were encouraged to modify, expand, polish, and experiment with instructional practices that improved their efficacy and improved pedagogical content expertise.

\section{Conclusions and Limitations}

An increasing trend exists to move to online delivery of literacy clinical courses, and this research shed light on how technologies and other aspects of an online literacy clinic can support candidates working as literacy coaches and reading specialists and prepare them for leadership roles in their school districts. The findings reveal that the specific incorporated technologies and other aspects of an online literacy practicum course delivery worked in terms of supporting the quality of learning and increasing the efficacy of graduate students. These findings are consistent with previous research that describes the process of moving a literacy clinic online in order to offer the highest level of efficacy (Bodzin \& Park, 2016;Caywood \& Duckett, 2019;Vokatis, 2018).

Although recent research literature defines online delivery systems, few studies have actually focused on online practicum instruction and learning via an online literacy clinic. A few studies have focused on plausible learner outcomes related to delivery system variables to test models of teaching in the design of an online literacy clinic (Bodzin \& Park, 2016). Future research should determine if a synchronous and asynchronous learning environment provides the highest level of efficacy and the most effective learning experiences for graduate students (Caywood \& Duckett, 2019).Specifically, future studies need to show that a synchronous and asynchronous format best fits a particular pedagogy used by instructors and enhances literacy clinics because the literacy coaches tutor struggling readers in one-on-one sessions in which they are required to make significant use of technology in their instruction (Wang \& Newlin, 2000).

The generalizability of the results of this study's limited due to the small number of participants. Replicating this study on a larger scale using numerous literacy clinics throughout the nation will render results with increased generalizability. Alongside the adoption of online literacy clinics, future research findings will advance theoretical understanding on how to implement an online course and practicum in a way that expands graduate students' pedagogical and content expertise.

\section{References}

Allen, I. E., \& Seaman, J. (2013). Changing course: Ten years of tracking online education inthe United States. http://www.onlinelearningsurvey.com/reports/changingcourse.pdf

Atkinson, T.S., \& Colby, S.A. (2006). Who's teaching, who's learning? Analyzing the professional growth of graduate student tutors. Mentoring \& Tutoring: Partnership in Learning, 14(2), 227-245. https://doi.org/10.1080/13611260500493642

Beattie, J., Spooner, R., Jordan, L., Algozzine, R., \& Spooner, M. (2017). Evaluating instruction in distance learning classes. Teacher Education and Special Education, 25(2), 124-132. https://doi.org/10.1177/088840640202500204

Bodzin, A., \& Park, J. (2016). Factors that influence asynchronous discourse with pre-service teachers on a public, web-based forum. Journal of Computing in Teacher Education, 16, 22-30.

Caywood, K., \& Duckett, J. (2019). Online vs. on-campus learning in teacher education. Teacher Education and Special Education, 26(2), 98-105. https://doi.org/10.1177/088840640302600203

Coulter, G. (2004). Using one-on-one tutoring and proven reading strategies to improve reading performance with adjudicated youth. Journal of Correctional Education, 55(4), 321-333.

Crossman, A. (2019). An overview of qualitative research methods.https://www.thoughtco.com/qualitative-researchmethods-3026555

Frey, T. (2008). Determining the impact of an online practicum facilitation for in-serviceteachers. Journal of Technology and Teacher Education, 16(2), 181-210.

Helfrich, S. R., \& Smith, W. E. (2011). Moving a graduate reading program online whilecontinuing to maintain program rigor and meet standards. College Reading AssociationYearbook,34, 105-119. 
Houge, T.T., Geier, C., \& Peyton, D. (2008). Targeting adolescents' literacy skills using one-to-one instruction with research-based practices. Journal of Adolescent \& Adult Literacy, 51(8), 640-650. https://doi.org/10.1598/jaal.51.8.3

International Literacy Association (2017). International Literacy Association Standards.https://literacyworldwide.org/getresources/standards/standards-2017

Karabulut, A., \& Correia, A. (2008). Skype, Elluminate, Adobe Connect, Ivisit: A comparison of web-based video conferencing systems for learning and teaching. In K. McFerrin et al. (Eds.), Proceedings of Society for Information Technology \& Teacher Education International Conference 2008 (pp. 481-484). AACE.

Li, Q., \& Akins, M. (2005). Sixteen myths about online teaching and learning in higher education: Don't believe everything you hear. Tech-Trends,49(4), 51-60.https://doi.org/10.1007/bf02824111

Lilienthal, L. K. (2014). Moving the university reading clinic to an online setting. College Reading Association Yearbook, 36, 179-195.

Lilienthal, L. K., Pottho, D., \& Anderson, K. E. (2017). The development of an online,graduate practicum course. The Delta, Kappa Gamma Bulletin, 84(1), 42-52.

Manset-Williamson, G., \& Nelson, J.M. (2005). Balanced, strategic reading instruction for upper-elementary and middle school students with reading disabilities: A comparative study of two approaches. Learning Disability Quarterly, 28(1), 59-74. https://doi.org/10.2307/4126973

McKenna, M.C., \& Walpole, S. (2019). Assistive technology in the reading clinic: Its emerging potential. Reading Research Quarterly, 42(1), 140-145.https://doi.org/10.1598/rrq.42.1.6

Penney, C.G. (2002). Teaching decoding skills to poor readers in high school. Journal ofLiteracy Research, 34(1), 99120.https://doi.org/10.1207/s15548430j1r3401_4

Peterson, S. S., \& Slotta, J. (2009). Saying yes to online learning: A first-time experience teaching an online graduate course in literacy education. Literacy Research and Instruction,48(2), 120-135. https://doi.org/10.1080/19388070802226303

Quatroche, J. D., \& Wepner, B. S. (2008). Developing reading specialists as leaders: Newdirections for program development. Literacy Research and Instruction 47(2), 99-115.https://doi.org/10.1080/19388070701878816

Sanders, K. J. (2014). Building a quality online reading specialist program. Journal of ReadingEducation,39(2), 32-34.

Strauss, A. L., \& Corbin, J. (1990). Basics of qualitative research (Vol. 15). Sage.

Vokatis, B. (2018). Reflections from the first phase of teaching online literacy clinics: Changes tothe initial perspectives and future considerations. Literacy Practice and Research,43(3),24-31.

Wang, A. V., \& Newlin, M. H. (2000). Characteristics of students who enroll and succeed in psychology web-based classes. Journal of Educational Psychology, 92(1), 137-143.https://doi.org/10.1037/0022-0663.92.1.137 